Revista Portuguesa de História

t. XXXI, Vol. 2(1996)

\title{
AS CIDADES E O PODER NO PERÍODO FILIPINO*
}

\author{
ANTÓNIO DE OLIVEIRA \\ (Universidade de Coimbra)
}

1. Cada geração desfaz e refaz a história. Teia refeita não propriamente pelo contributo de novos dados, mas pelos fios de novas concepções. Cada geração, com efeito, busca a sua identidade no passado e projecta-se no porvir, confiscando a anamnésia ou restituindo a memória pertinente. Por isso a história, como construto intelectual, é sempre uma história contemporânea, para além de biográfica'.

*A base deste texto foi apresentada numa conferência proferida na Biblioteca Municipal de Santarém, em 18 de Abril de 1996. Publica-se, agora, num volume de homenagem à memória do Prof. Doutor Salvador Dias Arnaut, cultor da história local e que foi detentor de uma das melhores colecções particulares de monografias integradas neste domínio historiográfico. Com saudade, afecto e gratidão lembro o Professor amigo com quem convivi desde o fim dos anos cinquenta. Sentimento que gostaria de espalhar pelos ventos e horizontes de Germanelo, esse castelo imperfeito guardião de sonhos inacabados. Do Doutor Salvador Dias Arnaut e de todos quantos, como eu, subiram em sua companhia, por veredas íngremes, ao cume das ameias. Que a eternidade do sonhar embale e fortaleça a lembrança do presente.

'Richard Harvey Brown, Social Science as Civic Discourse. Essays on the Invention. Legitimation and Uses of Social Theory. Chicago, The University of Chicago Press, s. d., p. 108; Lucette Valensi, Fábulas da Memória. A gloriosa batalha dos três reis. Porto, Asa, 1996, p. 17 s.; António de Oliveira, D. Duarte, Pátria e Memória, "Beira Alta", vol. L, 1991, p. 432. 
Neste sentido da história como teia de Penélope, os anos de setenta do nosso século desfizeram, pelo menos na Europa, a trama da paixão da razão, reconduzindo-nos a metáforas não mecanicistas pela revalorização do simbólico, a busca da expressão do sentir e a renovação do imaginário. A objectividade consiste em considerar os outros como diferentes de nós e não mergulhados numa corrente de intersubjectividade que os torna idênticos.

Neste plano da diferença avultam, na história política, na história do poder, os poderes múltiplos, as decisões centrais e infranacionais, pelo que está anunciada a morte do Estado "como modelo de organização política" racionalizada e o "advento de uma nova era civilizacional"². Fim do imaginário do Estado, do Estado-Nação que nos foi legado pelo liberalismo oitocentista, em favor de formas mais flexíveis de organização. Formas de poder plural, não apenas estatal, modeladoras do habitus pelo qual o homem se culpa ou inculpabiliza e que têm como suporte espacial, historicamente, as repúblicas da república global, para usar uma expressão de João Pinto Ribeiro, ojuiz de fora de Pinhel no período filipino e desembargador da dinastia de Bragança.

2. O tempo de hoje, como se sabe, é um tempo de construção de formas políticas de maior participação e não apenas de representação, integradas numa política económica global "que define as condições locais de paz e prosperidade" ${ }^{3}$ É de novo um tempo de poder local que pretende ser mais do que limitador dos assaltos estatais, centro de autonomia decisória em vez de parcela de "um aparelho de

${ }^{2}$ António Manuel Hespanha, Pré-compréhension et savoir historique. La crise du modèle étatiste et les nouveaux contours de l'histoire du pouvoir, "Rättshistoriska Studier", 1993, Band XIX, p. 50-51.

${ }^{3}$ Henry Teune, Local Government and Democratic Political Development, "The Annals of the American Academy of Political and Social Science", vol. 540, Julho 1995, p. 12. 
governo nacional" ${ }^{4}$. Por isso, se a historiografia, como disse há pouco, reflecte as vivências do seu tempo, o tempo historiográfico de agora é necessariamente o tempo novo da história das localidades com governo autónomo e autogestão dos seus problemas. Poder local que gostaríamos de observar, antes da segunda revolução democrática iniciada pelos anos noventa do nosso século, a partir de um padrão citadino mais de natureza majestática e soberana do que imagem conflituosa de um paradigma estadual centrípeto concebido pelo absolutismo e liberalismo. Anotação intencional de uma matriz que porventura será mais uma diferença do que uma originalidade de apresentação, dado que já no período filipino havia quem assim pensasse e diversos autores têm destacado as relações entre poder concelhio e regime senhorial na Idade Modernas.

Santarém, com um nobre currículo de liberdade e um exemplo ímpar na procura da manutenção da independência em 1580 é, simbolicamente, local adequado, e não apenas a propósito, para relembrar e eventualmente para repensar essa autonomia matricial. Liberdade de uma cidade, com já tão notáveis estudos sobre a sua história e, nomeadamente, no período do governo dos reis Filipes, história entretecida na história global dos outros centros urbanos, da qual é inseparável. As pátrias terminam onde a pátria começa.

3. A globalização das comunicações poderá vir a deslocar da cidade o centro da inovação. Aqui, porém, se continuam a buscar os

Francesco Kjellberg, The Changing Valúes of Local Government, "The Annals of The American Academy of Politicai and Social Sciency", vol. 540, Julho 1995, p.4243. Sobre o tempo conjuntural da história das localidades, António de Oliveira, Problemática da História Local, in " Faial e a Periferia Açoreana nos Séculos XVXIX". Actas do Colóquio. Horta, 1995. [O colóquio e o texto são de 1993].

'Por exemplo, José Ignacio Fortea Pérez, Poder realy poder municipal en Castilla en el siglo XVI, in Reyna Pastor e outros, "Estruturas y Formas del Poder en la Historia". Ponencias. Salamanca, Ediciones Universidad, 1991, p. 117-153, cujo teor seguimos. 
dinamismos, embora estes comecem nostalgicamente a tomar a forma da cor da pedra da montanha ou do verde dos campos que estruturaram a personalidade de muitos dos que a habitam, mas nela não nasceram ${ }^{6}$. Antes de ser memória, que a paisagem reconstruída reflectirá, continua a cidade a andar associada a uma certa forma de civilização e de desenvolvimento económico. Civilização "inventora do homem moderno" (Muchembled), o qual procurou cultivar os campos à sua imagem, levando os rurais seiscentistas a reagirem à disciplina envolvente, revoltando-se antes de se submeterem ou se adaptarem aos novos modelos coercitivos da justiça régia ou eclesiástica.

É através da cidade, da taxa de urbanização e, sobretudo, do tamanho dos centros urbanos que, com efeito, se tem procurado explicar o desenvolvimento de Portugal (ou melhor, a falta dele) ${ }^{7}$. Como concluiu Paul Bairoch num conhecido estudo, o factor tamanho das cidades - até um certo nível, bastante elástico- constitui um elemento positivo do ponto de vista do processo de desenvolvimento económico" ${ }^{\prime}$. O crescimento dos centros urbanos, porém, tem componentes positivos e negativos, sendo a diferença entre ambos que dita o seu tamanho. De qualquer modo, "cidade e sistema de cidades não são respostas sistémicas a algumas necessidades económicas"'. Múltiplos factores intervêm no crescimento urbano

${ }^{6}$ Para as ideias deste e do período anterior, Leonardo Benevolo, A Cidade na História da Europa. Lisboa, Editorial Presença, 1995, p. 15.

'Vitorino Magalhães Godinho, Estrutura da Antiga Sociedade Portuguesa. Lisboa, Arcádia, 1975, $2^{a}$. ed.; José Gentil da Silva, Au Portugal: structure démographique et développement économique, in "Studi in Onore di Amintore Fanfani", vol. Il, Milão, 1962; idem, Vida urbana e desenvolvimento:Portugal, país sem cidades, "Arquivos do Centro Cultural Português", vol. 5 (1972), p. 734-746; António Manuel Hespanha, Cities and state in Portugal, "Theory and Society, vol. 18, 1989, p. 707-720.

${ }^{8}$ Paul Bairoch, Taille des Villes, Conditions de Vie et Développement Economique, Paris, EPHESS, 1977, p. 375.

${ }^{\circ} \mathrm{Carol}$ A. Smith, Types of city-size distributions. A comparative analysis, in 
e na hierarquia das cidades, e não apenas os de natureza económica. Talvez por isso mesmo apela-se para a criação de cidades médias ${ }^{10}$.

As cidades, reescrevia-se em Portugal no século XVII, não deviam ser muito grandes nem muito pequenas, seguindo a mediania aristotélica, de modo a que fosse possível ouvir em todos os cantos a voz do pregoeiro, isto é, onde a sociabilidade fosse a de uma comunidade $^{11}$. Pequenas eram as cidades em boa parte da Europa, antes da revolução industrial. O que então se manifestava, com excepção dos lugares centrais, era, com efeito, pequenas cidades, um pouco como no Portugal de então. Tanto a França como a Inglaterra, por exemplo, estavam crivadas de pequenas "villes" e de "country-towns"'2. E em Portugal, pela mesma altura (1801), notava-se igualmente uma maioria de pequenos aglomerados urbanos. A estrutura francesa e inglesa é ultrapassada depois de 1840, mas a de Portugal do início do século XIX manter-se-á até $1864^{13}$.

Tanto as cidades como as vilas principais, como se escrevia no período filipino, têm "a mesma polícia e curiosidade", o que denota

"International Studies in Demography Urbanization in History. A Process of Dynamic Interactions", editado por Ad van der Woude, Jan de Vries and Akira Hayami, Oxford, Clarendon Press, 1990, p. 42.

${ }^{10}$ Bernard Lepetit e Jean-François Royer, Croissance et taille des villes: contribution à l'étude de l'urbanisation de la France au début du XIX siècle, "Annales, ESC", Paris, 1980, n- 5, p. 987-1010. Sobre modelaçao do sistema urbano, Teresa Barata Salgueiro, A cidade em Portugal. Uma geografia urbana, Porto, Edições Afrontamento, 1992, p. 55 s.

"Manuel Botelho Ribeiro Pereira, Dialogos Moraes e Politicos. Viseu, 1955, p. 137.

${ }^{12}$ Jacques Dupâquier, dir., Histoire de la Population Française, Paris, Presses Uuiversitaires de France, 1988, tomo III, p. 177; Peter Borsay, The English Urban Renaissance. Culture and Society in Provincial Town, 1600- 1770, Oxford, Clarendon Press, 1989, p. 4 s.; David Hey, coord., The Oxford Companion to Local and Family History, Oxford, Oxford University Press, 1996, p 443, voc. towns.

${ }^{13}$ António de Oliveira, Migrações internas e de média distância em Portugal de 1500 a 1900, "Arquipélago". Série História — In Memoriam Maria Olímpia Rocha Gil, vol. I - 1, Estudos gerais, p. 325, com bibliografia. 
a assunção de funções semelhantes ${ }^{14}$. A designação de cidade, no entanto, andou associada até inícios do século XIX, como é sabido, à sede episcopal, embora haja conhecidas excepções. Por este motivo, as vilas com nobreza de cidade eram designadas por vilas notáveis, qualificativo atribuído a Santarém pelo menos já na primeira metade do século XV.

O fenómeno urbano, no entanto, é, em termos numéricos, um fenómeno menor. Com efeito, num conjunto de de 762 unidades administrativas, consignadas no numeramento de $1527-1532^{15}$, ou ao lado das cerca de $860 \mathrm{com}$ autonomia jurisdicional por volta de $1640^{16}$, totalizando umas 3818 paróquias $^{17}$, as cidades e vilas notáveis, nestas incluindo pelo menos uma intitulada de excelente, não ultrapassavam o número de trinta, ficando-se por dezanove as localidades expressamente designadas por cidades em $1640^{18}$. Número de cidades e vilas principais, equiparadas a cidade, que, em termos redondos, equivale em 1640, sem coincidir, às 32 capitais de comarcas de então. Cidades e vilas cuja fundação ao longo do tempo é bem conhecida graças ao labor de diversos autores, sendo de toda a justiça salientar o que sobre esta temática e o surto regional tem publicado o Prof. Veríssimo Serrão ${ }^{19}$.

${ }^{14}$ Manuel Botelho Ribeiro Pereira, oh. cit., p. 139.

is Cômputo de João José Alves Dias, Gentes e Espaços. (Em Torno da População Portuguesa na Primeira Metade do Século XVI). Lisboa, 1992, (polic.) p. 386.

${ }^{16}$ António Manuel Hespanha, As Vésperas..., p. 99 s.; idem, Cities and the state in Portugal, "Theory and Society", vol. 18,1989, p. 716, onde refere cerca de 950 pequenas comunidades.

Número explicitado em 1640 pelo governador do Algarve. Em 1790 seriam 3 915, segundo um almanaque para este ano. (BUC, cota 0945, "17" ALM, p. 453).

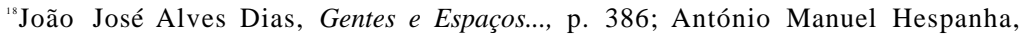
oh. cit., p. 716; Joaquim Veríssimo Serrão, Uma Estimativa da População Portuguesa em 1640. Lisboa, 1975, p. 239. ( Sep. de "Memórias da Academia das Ciências", vol. XVI, 1975); César Oliveira, História dos Municípios e do Poder Local. (Dos Finais da Idade Média à União Europeia). Círculo de Leitores, 1996, p. 67 s.

${ }^{19}$ Joaquim Veríssimo Serrão, A concessão do foro de cidade em Portugal dos séculos 
As cidades, como genericamente as outras unidades municipais, possuíam um território. Por volta de 1640 , as cidades e seus alfozes representavam, em termos de superfície, cerca de um quinto da área do país e albergavam, na sede e termo, mais de um quarto dos habitantes de Portugal $^{20}$. Santarém teria então à volta de 25000 habitantes concelhios, cabendo ao perímetro urbano uns quarenta por cento, ou mais. Uma incerteza que há muito deveria estar desfeita, se efectivamente já não está ${ }^{21}$.

4. As cidades são, a um tempo, universidades, corpo de corpos, e poder concelhio e justiça. Poderes múltiplos que de modo comum convivem uns com os outros, não podendo o estudo urbano desligar-se de nenhum deles, ignorar a sua coexistência.

Vista através do poder, a cidade, porém, como de modo genérico todo o poder municipal, surge como um espaço autónomo e descentralizado, por vezes em conflito com o poder régio, mas predominando uma atitude de paz e concórdia estabelecida por um pacto fundador.

Ao estudar-se o poder, torna-se necessário, com efeito, distinguir o fundamento do poder das formas do seu exercício. O exercício do poder régio sob a forma denominada absolutismo dos séculos XVI a XVIII, que bem conhecemos, radica, no entanto, exactamente como a democracia, num contrato bem teorizado já no século XIII. Os

XII a XIX, "Portugaliae Historica", vol. I, 1973, p. 13-80; Pedro de Azevedo, As cartas de criação de cidade concedidas a povoações portuguesas, "Boletim da Segunda Classe da Academia das Ciências", vol. X, 1917, pp. 930-971; idem, Cartas de vila, de mudança de nome e de titulo de notável das povoações da Estremadura, "Boletim da Segunda Classe", Academia das Ciências de Lisboa, vol. XIII, fasc. 3, 1919, p. 1067-1150. (Data de publicação. 1921).

${ }^{20}$ Cálculos efectuados a partir dos dados publicados por António Manuel Hespanha no segundo volume da edição policopiada (a $1^{2}$ ) de As Vésperas do Leviathan.

${ }^{21}$ Julgo não desconhecer o que está publicado. 
laços societários, em linguagem medieval, "implicam um sentido de participação voluntária e contratual", como se tem sublinhado ${ }^{22}$. Contrato que é um sacramento e como contrato sacramental, através do juramento mutuamente prestado pelo rei e pelas cidades e vilas, se constitui o poder autónomo e descentralizado em relação à concentração régia. Liberdades municipais formalizadas por um rei ou outro senhor por meio de um foral, pelo menos em Portugal e no resto da Península Ibérica, e não propriamente através de um acto de conquista, de libertação. Liberdades que cada rei, ao ser aclamado, se compromete a guardar, em testemunho de fidelidade recíproca, e que nos remetem para um tempo primigénio em que as repúblicas transferiram para o rei e senhor a sua soberania e majestade, mas reservando para si algumas liberdades e franquezas. Reserva que lhes permitia eleger novo rei, se fosse caso disso.

Significam estas proposições que algo de realengo se comunica às câmaras através do contrato inicial. O poder concelhio, obviamente, reconhece superior, ao contrário do rei que é soberano. Acima de tudo está o poder régio, como a dogmática e o simbolismo exprimem.

Ao entrar o rei numa cidade pela primeira vez depois de aclamado, o vereador mais velho oferece-lhe a cidade através das chaves que o monarca toca com a mão em sinal de posse, devolvendo-as depois. E ao mesmo tempo, numa arenga apropriada de boas vindas, o orador oficial pede, numa referência obrigatória, a conservação dos privilégios e liberdades de que goza a cidade ${ }^{23}$.

Com a cerimónia, a cidade reconhece superioridade, mas as

"Alain Boureau, Pierre de Jean Olivi et l'émergence d'une thèorie contractuelle de la royauté au XIIIe, in "Représentation, Pouvoir et Royauté à la fin du Moyen Age". Actes du colloque [...] edités par Joël Blanchard, Paris, Picard, 1955, p. 172.

${ }^{23}$ Documento publicado por Joaquim Veríssimo Serrão, A concessão do foro de cidade, p. 36-37, nota 107. 
repúblicas municipais conservam parte desta superioridade quando administram justiça, sendo a honra que deriva desta administração uma honra superior e, por isso mesmo, as câmaras mantêm na igreja cadeira majestática, ao lado do juiz régio ${ }^{24}$. Dignidade que igualmente se revela na obrigatoriedade do povo acompanhar a câmara em actos públicos de procissões, como esta é obrigada a acompanhar o rei ou a bandeira régia. Correspondência e reciprocidade entre rei e município, pessoa moral, que a imagem de casamento entre o rei e o reino espelham, comunicando o monarca directamente às cidades e vilas notáveis os acontecimentos faustos e infaustos da monarquia. Unidade entre rei e município que as cortes, por outro lado, consubstanciam.

Estas honras das câmaras são superiores às dos títulos e senhores de terras. Estes possuem apenas a honra que o rei lhes concede, a que "o rei larga de sua majestade", enquanto as câmaras "retêm parte do que de si largaram aos príncipes", na expressão de João Pinto Ribeiro, o que constitui uma diferença radical.

Esta imagem de contrato e consenso, de liberdade, soberania e dignidade das repúblicas municipais, foi defendida no foro, nos anos vinte do século XVII, pelo juiz de fora de Pinhel, o referido João Pinto Ribeiro, argumentando contra o alferes da excelente vila que pretendia, como homem, reverências por parte da edilidade.

Como os títulos e os grandes, comenta o advogado, as câmaras têm bandeira que as simboliza e identifica e, como eles, são também senhorios, exercendo sobre o termo concelhio um vasto domínio. Em todo o concelho, por sua vez, o rei mantém o domínio sobre as dadas dos ofícios camarários e seus bens, mas sobre eles as câmaras detêm a propriedade e o uso, exercendo jurisdição no exercício da

${ }^{24}$ Uma sentença em contrário encontra-se publicada em Pegas, Ad. Ord. Reg., tomo V, p. 152 . 
sua superioridade ${ }^{25}$. Em 1703 ainda as Câmaras, como a de Coimbra, podiam afoitamente mandar exarar ao seu escrivão, como resposta à atitude menos submissa de um Mestre de Campo de soldados auxiliares, que por sinal será, mais tarde, vereador fidalgo, que na cidade e termo o senado "era cabeça e governo", não obstante a preparação bélica geral em curso ${ }^{26}$. Com mais à vontade, certamente, podiam replicar no período filipino, pelo que a política global do monarca, para ser apoiada, tinha de recorrer a estratégias diversas.

3. Dentro da metáfora organicista, Lisboa era cabeça do reino e, como tal, em virtude de antiga concessão confirmada em cortes, podia comunicar directamente com a corte quando as circunstâncias do bem comum o exigissem, assim como o juiz do povo, pelo menos ao tempo das guerras da Restauração, podia entrar no Paço até à sala a partir da qual só passavam fidalgos. Esta prerrogativa de Lisboa foi coartada ao tempo da preparação da vinda de Filipe III a Portugal, a qual se acabou por efectuar em 1619, pelo que nas cortes deste ano Lisboa pediu não apenas a confirmação do privilégio, mas também o poder de comunicar com as cidades e capitais de comarca, provavelmente relembrando a oposição inicial que nesta matéria anos antes tinham levantado Porto e Santarém a propósito da preparação da viagem régia ${ }^{27}$. Privilégio simulacro da união do reino com o rei

${ }^{25}$ João Pinto Ribeiro, Segunda relação, in "Obras varias sobre varios casos com tres relaçoens de direito, e lustre ao Dezembargo do Paço, às eleyções, perdões, \& pertencas de sua jurisdição compostas pelo doutor [...]". Coimbra, 1719. Para além deste autor, aproveitámos também o texto de Fortea Perez acima citado.

${ }^{26}$ Sérgio Cunha Soares, O Município de Coimbra da Restauração ao Pombalismo. Poder e Poderosos na Idade Moderna. Coimbra, Faculdade de Letras, 1995, p. 1414.

${ }^{27}$ Cortes de 1619, capítulos do terceiro estado, n. ${ }^{\circ}$ 62; António Manuel Hespanha, O governo dos Áustrias e a "modernização" da constituição politica portuguesa, "Penélope", 2 (1989), p. 50-72. Já em 1602, por exemplo, Lisboa, com procuração dos lugares do primeiro banco de cortes, havia embargado na chancelaria o registo de um 
fora do tempo de cortes, as quais, para além das iniciais de Tomar (1581), só em 1619, no período filipino, se reuniram.

Como é sabido, as cidades e vilas apresentavam em cortes as reivindicações locais e, para além delas, o sentir geral do chamado terceiro estado, à semelhança do clero e nobreza.

As preocupações locais de Santarém, espelhadas nas cortes de 1641, revelam-se bem no facto de não querer pagar os 100000 réis impostos nas suas rendas e destinados aos estudantes médicos cristãos-velhos da Universidade de Coimbra, sob pretexto de outras cidades não contribuírem, e em questões de sua soberania. Entre estas ficaram explicitadas as usurpações de jurisdição em Montargil, Golegã, Azambujeira e na feira das Virtudes ${ }^{28}$.

Nesta feira, que durava três dias, o corregedor da comarca usurpou, em 1640, a jurisdição que nela exercitava o juiz de fora de Santarém, na qual se incluía a almotaçaria de todos os mantimentos. Usurpação igualmente praticada em Montargil e Golegã.

Golegã foi desmembrada do termo de Santarém em $1534^{29}$ e

Inquisição portuguesa face ao projecto do $3^{\circ}$ perdão geral para os cristãos novos portugueses. Porto, 1993, p. 199. (Sep. da Revista da Faculdade de Letras, II série, vol. X. Porto, 1993, p 177-203).

${ }^{28}$ Capítulos especiais de Santarém, cortes de 1641 e 1642. Servimo-nos da cópia existente na Sala Gama Barros, Instituto de História Económica e Social da Faculdade de Letras da Universidade de Coimbra. Vide também António Manuel Hespanha, $A$ "Restauração" portuguesa nos capítulos das cortes de Lisboa de 1641, "Penélope", n. ${ }^{\circ}$ 9/10 (1993), p. 47. Em 14 de Abril de 1640 havia na feira das Virtudes 7 escrivães ( francaria, madeira, marçaria, linhos, fruta verde, ferramenta e sapataria e courama). (ANTT, Livraria, ms. 1194).

${ }^{29}$ Pedro de Azevedo, Cartas de vila, de mudança de nome e do titulo de notável das povoações da Estremadura. Coimbra, Imprensa da Universidade, 1921, p. 40-43. Sep. de "Boletim da Classe de Letras" da ACL, vol. XIII; António de Oliveira, A População das Comarcas de Leiria e Santarém em 1537. Coimbra, 1976, p. 260, nota 74. Em 1640 era senhor de Azambuja D. Francisco (ou Fernando?) Rolim de Moura. Em 1640, o corregedor que fez a avaliação dos ofícios explicitou:"nào achei doação feita a ele nem confirmação registada no livro da chancelaria". As rendas de Azambuja e Montargil foram então sequestradas "até mostrar doação confirmada". (ANTT, Livraria. ms. 1194; Joaquim Veríssimo Serrão, História de Portugal, vol. IV, p. 312). 
Montargil, por sua vez, em $1542^{30}$, havendo-se, no entanto, tornado autónomas, mas não independentes ${ }^{31}$. Com efeito, ojuiz de Santarém exercia nelas a função de ouvidor, cabendo-lhe, por exemplo, como se explicita para Montargil, fazer as eleições concelhias, sendo todos os oficiais eleitos confirmados pela câmara de Santarém e por ela se chamando os juízes. Em 1641 Santarém reivindica a jurisdição usurpada e, ao mesmo tempo, a restituição ao seu termo das referidas vilas, incluindo também Azambujeira ${ }^{32}$, então nas mãos de Lourenço Pires de Carvalho, doada no período filipino sob condição de "ficar sendo comarca de Santarém" ${ }^{133}$.

A usurpação das juridisções referidas foi efectuada, como refere a nobre vila de Santarém, pelas tiranias de ministros passados, mas as próprias aldeias do termo, como se verificou em Azinhaga, ao tempo da aclamação de D. João IV, podiam igualmente cometer abusos jurisdicionais ${ }^{34}$. Com efeito, os moradores de Azinhaga, certamente com o apoio do governo local, proclamaram também a

${ }^{30}$ Pedro de Azevedo, Cartas de vila...., p. 44-46.

${ }^{31}$ Pedro de Azevedo, Cartas de vila... p. 40-43, para Golegã; António de Oliveira, A População das Comarcas de Leiria e Santarém em 1537. Coimbra, 1976, p. 260, nota 74; Joaquim Veríssimo Serrão, História de Portugal, vol. IV, p. 312. D. António Rolim de Moura (1709-1782), primeiro conde de Azambuja, foi o "19º senhor de Azambuja e Montargil, por convenção feita por seu pai com seu parente D. João Rolim de Moura, $17^{\circ}$ senhor da referida vila", segundo informação que transcrevemos de Afonso Eduardo Martins Zúquete, Nobreza de Portugal e do Brasil. Vol. II. Lisboa, 1960, p. 367.

${ }^{32}$ O capítulo de cortes acrescenta ainda a vila de "Enguias". Erro toponímico da cópia?

${ }^{33}$ Vila erigida em 27 de Maio de 1633. (Pedro de Azevedo, Cartas de vila... p. 65-66; Joaquim Veríssimo Serrão, História de Portugal, vol. IV, p. 278; capítulos de Santarém apresentados nas cortes de 1641, cit.; ANTT, Livraria, ms. 1194. Azambujeira foi dada em 1633 a Lourenço Pires de Carvalho através de mercês devidas ao sogro. Pagou de meia anata, no tocante da elevação da aldeia a vila, 34500 réis; pela mercê da jurisdição ordinária de Azambujeira foram pagos 34860 réis de meia anata.

${ }^{34} \mathrm{Em} 1540$, Azinhaga tinha uns quatro ofícios, entre eles tabelião de notas, escrivão do judicial e alcaide. (ANTT, Livraria, ms. 1194; a fl. foi aparada pelo local onde estava inscrito o quarto ofício, de pouco rendimento). 
independência em relação a Santarém ao elevarem o lugar a vila e erguerem um pelourinho, símbolo da sua nova jurisdição. Acção popular que chegou a ameaçar de morte o juiz de fora de Santarém que servia de corregedor, o qual acorreu para repor a ordem. Justiça que Santarém reclama ainda nas cortes de 1642, sem a qual as outras aldeias poderiam seguir o exemplo de Azinhaga, proclamando-se vilas, segundo argumenta ${ }^{35}$.

Para a correcção de todas estas usurpações, a câmara de Santarém, esperançada na nova situação política e conhecedora dos meandros dajustiça, pediu que esta fosse feita sumariamente. De outro modo, seguindo a via ordinária, a câmara augura, como se exprime, que "nunca se restaurará cousa alguma do que propomos". O poder régio não permitiu esta via, mas autorizou a câmara a requerer o seu direito perante o Desembargo do Paço, ouvidos os donatários e as mais partes, o que em princípio dificilmente conduziria a qualquer restauração concelhia.

Para além do especificamente local, Santarém, como os outros membros do terceiro estado com assento em cortes, apresentaram em 1619 um vasto conjunto de intenções gerais, desenhando uma imagem do reino na qual se destaca um forte sentido de autonomia, um grito por melhor justiça, um apelo a favor dos estratos superiores do terceiro estado que viviam segundo a lei da nobreza, um bloqueamento social dos mesteirais, a repressão da gente de nação, um repúdio pela forma de governo dos governadores do reino em favor do vice-reinado e certas modificações quanto ao poder municipal, nomeadamente no que diz respeito à constituição dos vereadores da cidade de Lisboa.

"Nas cortes de 1642, Santarém pediu que as charnecas não fossem aforadas, apresentando, entre outros exemplos fundamentadores do prejuízo causado às suas rendas, uns matos aforados por 4000 réis "em que Braz Telles fez. hua villa". 
Portugal era então um país sem justiça. Tem-se já acentuado que os memoriais sobre esta questão reflectem um conflito entre os letrados dos conselhos e os membros das diferentes juntas constituídas directamente sob a tutela do valido e capazes de tomarem decisões com mais eficácia porque menos burocráticas e menos opositoras $^{36}$. Mas é inegável que não havia justiça contra os poderosos nem a sua clientela, como não havia poder régio capaz de suster o mando absoluto de tiranos como o comendador de Pontével, uma das melhores comendas da Ordem de Malta ${ }^{37}$. Esta comenda foi unida, desde cedo, à de $\mathrm{S}$. João de Alporão, de Santarém, podendo os comendadores, por este motivo, designarem-se por um dos topónimos ou por ambos. O paço das comendas unidas situava-se em Pontével e as violências de Frei Sebastião Pacheco Corte Real, praticadas na década de trinta, ficam subentendidas no título de um pequeno artigo que intitulei $A$ violência dos cavaleiros de S. João no período filipino ${ }^{38}$. Tempo em que é por vezes necessário distinguir, em relação ao rei, entre ter o poder e ter poder, o qual parece que não tinha em certas áreas regionais de mando. Parece, efectivamente, que nem sempre o poder régio tinha poder, tinha mando, pelo que não podia haver justiça, tanto a régia como a dos juízes ordinários. Pelo menos nas cortes referidas foi pedido que os senhores das terras grandes fossem obrigados a terem juízes de fora ou ouvidores nos seus estados, embora nem por isso os poderosos ficassem inibidos de paralisar a justiça contra si. É neste sentido, provavelmente, que

${ }^{36}$ António Manuel Hespanha, O governo dos Áustrias.... Para a problemática em geral, Dolores M. Sánchez, El Deber de Consejo en el Estado Moderno. Las Juntas "ad hoc" en Espana (1417-1665). Madrid, Ediciones Polifemo, 1993.

${ }^{37} \mathrm{~A}$ falta de justiça está representada nos capítulos do terceiro estado nas cortes de 1619 e em muitos outros documentos, como referi, por exemplo, em Poder e Oposição Política em Portugal no Período Filipino (1580-1640). Lisboa, Difel, 1991.

${ }^{38}$ Separata de Estudos e Ensaios em honra de Vitorino Magalhães Godinho. Lisboa, Sá da Costa, 1988. 
em 1636 o arcebispo de Braga, por exemplo, requereu juiz de fora para o seu senhorio, o qual dispunha de 13 coutos de juízes ordinários de primeira instância ${ }^{19}$. E os juízes dos órfãos das cidades e vilas notáveis, por sua vez, solicitavam as mesmas cortes de 1619, não deveriam ser perpétuos.

Falta de justiça punitiva e também carência de justiça distributiva, pelo que os procuradores do terceiro estado se opunham a que o poder supremo em Portugal fosse detido por governadores, dado que estes, como grandes senhores que teriam de ser, não davam garantias, em virtude da parentela e clientela, de fazerem justiça nem darem razão aos menores, que, como se lamentam, "tão oprimidos sempre foram e são".

As cortes foram sempre pelo menos um local de audiência e de deliberação, as quais os reis se esquivavam de convocar em virtude da oposição que poderia surgir por parte das cidades ${ }^{40}$. Assim sucedeu nos anos trinta de seiscentos, pelo que o poder régio, para se furtar à presumível oposição e por sugestão do governo de Lisboa, pensou reuni-las de modo restrito, o que não teve efeito em virtude da forte contestação que a ideia levantou. Dada a oposição a este simulacro de cortes, e não convindo ao poder régio convocá-las em termos institucionais acostumados, este pensou em obter o consentimento

Como é sabido, mas não considerado pelos autores que têm tratado recentemente esta problemática, os Senhores de terras não podiam colocar nelas juízes de fora sem autorização régia, advertindo o monarca que "deixem os Concelhos usar de suas eleições segundo nossa Ordenação" . (OF, liv. 2-, t.45, n 13; OM, liv. 20, t. 26, no 44). Uma síntese sobre a questão dos juízes de fora em César Oliveira, dir., História dos Municípios e do Poder Local. (Dos Finais da Idade Média à União Eumpeia). Círculo de Leitores, 1996, p. 183 s. e p. 150 para a Casa de Bragança, cujos privilégios para juízes de fora de algumas das sua terras se encontram sumariados em Manuel Inácio Pestana, $A$ Reforma Seiscentista do Cartório da Casa de Bragança, Lisboa, Fundação da Casa de Bragança, 1985.

${ }^{40}$ D. Francisco Manuel de Melo, Visita das fontes, in "Apólogos Dialogais". Prefácio e notas do Prof. José Pereira Tavares. Vol. I, Lisboa, Livraria Sá da Costa, 1959, p. $118 \mathrm{~s}$. 
ou o compromisso do reino, nas decisões em que este era necessário, através das cidades do primeiro banco, onde se sentava Santarém, como se sabe. A partir do bom exemplo destas cidades, as outras localidades, presumia-se, segui-las-iam, como se tentou ao longo da negociação da chamada renda fixa nos começos da década de trinta, essa década de todas as rupturas. Tentativa régia que começou, como seria de esperar, por procurar demover as respectivas vereações.

4. O bem comum, dentro de cada república, era gerido, ao contrário do que se passava por exemplo em Castela, como ficou consolidado desde Afonso $\mathrm{XI}^{41}$, por um corpo de magistrados eleitos de modo indirecto, entre os quais sobressaem os vereadores e os juízes, podendo estes serem nomeados pelo rei, chamando-se então, sintomaticamente, juízes de fora. Com excepção destes juízes, forçosamente sediados numa minoria numérica de circunscrições, as repúblicas locais eram governadas, efectivamente, por naturais do concelho, pelo menos até aos anos quarenta do século XVIII, época em que as grandes cidades passaram a ser dirigidas por fidalgos que afastaram a nobreza local e encetaram um exercício de poder à imagem do absolutismo régio, impondo-o localmente ${ }^{42}$, de modo a Bacelar Chichorro, nos finais do século XVIII, referindo-se à província da Estremadura, poder criticar "a ilimitada jurisdicção das Cameras, e seus abusos"43. Estava-se já a bom caminho de uma

\footnotetext{
${ }^{4}$ Para Castela, Paulino Iradiel, Formas del poder y de organización de la sociedad en las ciudades castellanas de la Baja Edad Media, in Reyna Pastor e outros. "Estructuras y Formas del Poder en la Historia". Salamanca, Ediciones Universidad. 1991, p. 23-49.

"Como têm acentuado, por exemplo, José Viriato Capela, Sérgio Cunha Soares e Nuno Gonçalo Monteiro.

${ }^{43}$ José de Abreu Bacelar Chichorro, Memoria Economico Politica da Provincia da Extremadura traçada sobre as instrucções regias de 17 de Janeiro de 1793 por [...].
} 
imagem de Estado que, como indicámos, tem uma morte anunciada nesta nossa década de noventa, iniciadora da segunda revolução democrática. Ao longo do século XVII, porém, o que parece predominar em Portugal, pelo menos até às cortes de 1674, data que aponto apenas como símbolo de intervenção e representação, é um fundo de governo de nobreza e povo, com excepção da tentativa de Castelo Melhor, o qual se não podia deixar de reflectir no exercício do poder local $1^{44}$.

Os principais gestores deste poder, ao serem eleitos, necessitavam de confirmação, sendo esta feita pelo rei, nas terras de sua jurisdição, pelo menos desde os inícios do século XVI quanto a algumas cidades e mesmo, no tocante a Lisboa, a partir pelo menos da década anterior $(1488)^{45}$.

Confirmar, como define João Pinto Ribeiro, dá apenas força ao confirmado, não acrescentando nada que não esteja já na sua natureza. A confirmação das vereações, porém, desde cedo passou a ser designada pelas palavras limpar ou apurar, as quais denotam, para além de um título de domínio, um acto de intervenção voluntária na escolha dos eleitos, o que permitia ao poder régio, como árbitro, inclinar-se para a facção que lhe fosse mais conveniente, sob pretexto

Edição organizada c prefaciada por Moses Bensabat Amzalak, Lisboa, 1943, p. 60. Liberdade "incompativel com o systema de hum Governo Monarchico, e propria somente ou dos antigos Póvos Livres, das cidades Anseaticas; ou dos Cantoens Suissos, em que cada huma, ou cada hum delles goza da authoridade suprema; mas alhea, e insuportavel dentro de huma Nação polida, em que o Rei he o unico Legislador". (Idem,p. 101).

${ }^{44}$ Para o desenvolvimento da ideia da obediência como base do governo, a partir da segunda metade do século XVII, vide, por exemplo, Michel Senellart, Les Arta de Gouverner. Du Regimen Mediéval au Concept de Gouvernement. Paris, Éditions du Seuil, 1995, p. 37 s.

${ }^{45}$ Eduardo Freire de Oliveira, Elementos para a Historia do Municipio de Lisboa. Tomo I,. Lisboa, 1882, p. 7. Para o apurar de 1525, p. 11. Manuela Mendonça, D. João II. Um Percurso Humano e Politico nas Origens da Modernidade em Portugal. Lisboa, Estampa, p. 314. 
purificador das impurezas eleitorais de que os homens eram capazes, não obstante a severidade da $1 \mathrm{ei}^{46}$.

A concentração do poder régio ao longo da Idade Moderna, expressa por esta e muitas outras formas, não se fez, no entanto, sem resistências locais. As repúblicas têm uma visão particularista, parcial, a monarquia uma visão global. Não se fala em liberdade, o que pressupõe uma arquétipa concepção generalizante, a redução do múltiplo ao uno, um espírito geométrico rectilíneo, mas de liberdades, de localidades, de tortuosas ruas direitas aos paços do concelho, excluindo os que não gozavam das suas leis. O limite do termo era uma fronteira, embora mais imposta pelo poder do que pela sociabilidade, como se manifestava em redor de cultos comuns. O espaço do poder régio, pelo contrário, é o do reino global. D. Pedro V não teria gostado de ver Alexandre Herculano a ensinar municipalismo no Curso Superior de Letras, que acabara de fundar, precisamente pela dificuldade de conciliação entre estas duas esferas $^{47}$. De aparência xenófobos, governados por naturais, os concelhos como poder só se uniam e comunicavam uns com os outros em questões que os transcendiam ou lhes eram comuns, como afinal, ainda hoje sucede, cujos melhores exemplos, no que diz respeito a

${ }^{46}$ Havia dois tipos de eleições: as que iam à corte (ou ao tribunal do senhorio, como a Junta da Casa de Bragança) e as feitas nas terras, as dos pelouros, as quais se regiam pelas Ordenações (filipinas a partir de 1603) e pelos regulamentos dados aos magistrados encarregados de efectuá-las. Os escrivães tinham formulários para cada situação, os quais nos permitem seguir a prática das eleições. Para o século XVII conhecem-se os dois tipos, estando recenseados uns e outros, sendo o exemplo conhecido mais antigo, para as eleições que vão apurar à corte, de 1605 (Loulé). O modelo das eleições na terra segue o alvará de 12 de Novembro de 1611 que ainda em 1641 se considera, num formulário, como regimento novo.

${ }^{47}$ António de Oliveira, Problemática da história local, cit. e, com outros desenvolvimentos, no texto com o mesmo título, a editar pela Câmara Municipal de Soure; Jorge Borges de Macedo, Unidade de poder e diversidade de situação nas áreas regionais em Portugal. Consequências metodológicas, in "Primeiras Jornadas de História Local e Regional", Lisboa, 1993. 
actividades quotidianas, nos chegam dos Açores, das ilhas de S. Miguel e S. Jorge, desde pelo menos o século XVI, de acordo com a documentação conhecida ${ }^{48}$.

Ao opor-se ao particular, e sobretudo à união dos poderes particulares, a visão global da monarquia criava resistências, as quais o poder régio foi procurando neutralizar quer pela introdução nas vereações de elementos que lhes fossem afectos e que através das redes sociais da parentela e clientela implantassem localmente os desígnios régios, quer através dos conhecidos mecanismos realengos do imposto e da guerra, armas decisivas de todas as políticas globais. Política régia contra a qual estavam as cidades no período filipino, sendo este um bom tempo para testar as autonomias locais e os laços de solidariedade entre os municípios.

Em troca dos seus privilégios, das suas liberdades, as cidades e as vilas deviam auxílio e conselho ao monarca. O primeiro exprimia uma dupla tributação, a de soldados e dinheiro necessário à guerra. A guerra não se faz sem homens, mas sem dinheiro não há exército e nem uma coisa nem outra as cidades estavam inclinadas, no momento, a conceder e muito menos a contribuir sob a forma de tributo permanente, qualquer que ele fosse, embora cobrar impostos justos, mas consentidos, fosse uma regalia da coroa.

Por vezes, como sucede com os encabeçamentos das sisas e, de certo modo, com os das jugadas, onde estas se cobravam por esta via, as cidades participavam nas tarefas régias em regime de autonomia e descentralização ${ }^{49}$. O sistema da cobrança das sisas gerais

${ }^{48}$ Maria Margarida de Sá Nogueira Lalanda, A Sociedade Micaelense do Século XVII. Estruturas e Comportamentos. Ponta Delgada, 1995, p. 478 s.; António dos Santos Pereira, A Ilha de S. Jorge (Séculos XV-XVII). Contribuição para o seu Estudo. Ponta Delgada, Universidade dos Açores, 1987, p. 323.

${ }^{49} J o s e ́$ Ignacio Fortea Perez, Poder real...., p. 124. A partir da Restauração, as câmaras vão ser solicitadas cada vez mais a participar na imposição e cobrança fiscais, parecendo ser esta, para os finais do século XVIII e princípios do século XIX, uma das 
por encabeçamento havia-se iniciado com D. João III e praticava-se, de modo continuado, desde o reinado de D. Sebastião, tendo o terceiro estado solicitado nas cortes de 1619 a continuação do sistema, embora sistematicamente em todas as cortes se pedisse o levantamento de semelhante tributo geral.

Para evitar este sentido perpétuo, as cidades procuravam contribuir por meio de serviços com caracter extraordinário, os quais terminavam quando cessavam as circunstâncias que lhe deram origem. Mas quer contribuíssem de um modo quer de outro, as cidades opunham-se à cobrança de impostos não constitucionais, não consentidos, não votados em cortes onde tinham assento por direito, ao lado da nobreza e do clero.

Precisamente nos anos trinta, num contexto epidémico de sucção fiscal, o governo de Madrid pretendeu impor a Portugal um avultado tributo justificado pela necessidade de recuperar o ultramar, mas sem reunir cortes, as quais lhe não convinha convocar. Contra semelhante prepotência do poder régio, as cidades vão resistir pacificamente, antes de se revoltarem, procurando o monarca, pelos meios que lhe foi possível, persuadir e negociar antes de impor por regalia, provocando então a revolta, uma vez quebrado o contrato primigénio entre cidades e o rei.

Um dos pontos de apoio desta luta, que já tive oportunidade de contar, situa-se no fim do ano de 1634 com a chegada a Portugal do novo vice-rei, a princesa Margarida, que veio acompanhada, entre outras personalidades, pelo assessor Marquês de la Puebla, que

principais actividades dos vereadores, vistos então como colaboradores do Estado. Cf., por exemplo, José Viriato Capela, O Minho e seus Municipios. Estudos EconómicoAdministrativos sobre o Município Português nos Horizontes da Reforma Liberal. Braga, Universidade do Minho, 1995. Para o "compromisso" entre os poderes municipais e a coroa, vide Nuno Gonçalo Monteiro, in César de Oliveira, História dos Municipos,cit,p. $121 \mathrm{~s}$. 
deveria ser, de acordo com instruções secretas, o verdadeiro vice-rei encoberto, e de um secretário de Estado de nome Miguel de Vasconcelos, ligado a Santarém pelo casamento e por rendimentos, pelo menos, que aí passou a deter ${ }^{50}$.

Na longa história da base impositiva da nova renda, havia-se já chegado a acordo, ao iniciar-se o último vice-reinado, quanto ao princípio, proposto pela cidade de Lisboa, de se aumentar o cabeção das sisas e impor o real de água. Para passar dos princípios aos factos, tornava-se necessário que as câmaras aceitassem os novos contratos que teriam de ser elaborados com cada uma de per si, pelo que o poder régio desencadeou uma vasta acção persuasória, julgando que bastaria convencer as câmaras do primeiro banco, onde então se sentavam, recorde-se, Santarém, Lisboa, Évora, Coimbra e Porto, para todo o reino ficar conforme.

A câmara de Évora foi a primeira a ser convencida através da corrupção, embora sob uma forma que politicamente não compensava, sendo o mesmo processo tentado em Santarém, mas sem resultado.

Para mais facilmente vergar as cidades ao gosto do poder régio, foram colocados vereadores convenientes (como se lê no documento que estamos a seguir) pelo menos em algumas câmaras, o que aparentemente era fácil através do apuramento das pautas, ou pela nomeação, como está provado, de escrivães camarários igualmente em sintonia com o poder central e capazes de influenciarem as decisões. Mas em muitos locais a estratégia não resultou, como aconteceu em Santarém, vila notável também pelos exemplos de liberdade de que sempre foi capaz. Permita-se-me, por isso, que apresente alguns pormenores desta negociação, dado que suponho que estão pouco divulgados, para além das referências que lhe tenho feito.

${ }^{50}$ António de Oliveira, Poder e Oposição Politica, cit., entre outros trabalhos meus. 
Para Santarém são bem conhecidos os vereadores em exercício entre os anos 1631 -1635, graças à meritória investigação do Mestre Martinho Vicente Rodrigues. Faltam indicações, pelo menos no quadro do autor, para os anos de 1636 e 1637, cujos livros de vereações não se encontram, como sintomaticamente sucede em muitas outras municipalidades, embora pareça poder supor-se que os vereadores de 1636 são os mesmos de 1635, havendo permanecido, assim, na gestão da câmara, os mesmos vereadores ao longo de seis anos seguidos. Estes vereadores chamam-se Luís de Oliveira Vasconcelos, Diogo Carvalho Pereira e Lopo Tavares de Sousa, embora este, já em 1635, tenha sido vereador de barrete, segundo parece ${ }^{51}$.

Estes vereadores, já ao tempo do governo de D. Diogo de Castro se haviam oposto ao real de água e aumento da quarta parte do cabeção das sisas e nesta posição se mantinham nos inícios de 1635 , pelo que foram tentados ou projectados diversos meios para convencer Santarém, como recomendou confidencialmente o poder sediado em Madrid. Entre as tentativas conta-se a ida a Santarém de um ouvidor e a chamada a Lisboa, por parte de Miguel de Vasconcelos, de algumas personalidades, entre elas um seu cunhado residente em Santarém. A presença de familiares do Secretário de Estado, que em Santarém parece também não ter gozado de simpatia enquanto vivo ${ }^{52}$, tornava difícil a actuação directa de Miguel de Vasconcelos, o qual procurou um defensivo distanciamento dos

Martinho Vicente Rodrigues, Santarém no Período dos Filipes (1580-1640). Vol. I. Estudo Histórico. Lisboa, 1995, p. 153-155. (Diss. polic). Lopo Tavares de Sousa é uma pista a calcorrear em busca daas razões da substituição.

${ }^{52}$ Nos textos de sua defesa, Miguel de Vasconcelos explicita a animadversão que suscita a sua actividade em favor das tributações régias, traduzindo-se na má vontade em relação aos seus interesses pessoais e no próprio atentado que sofreu cm 1634 . Sobre este vide António de Oliveira, O Atentado contra Miguel de Vasconcelos em 1634. Coimbra, 1980. Separata de O Instituto, vols. CXL-CXLI. 
vereadores em exercício, talvez pelo facto também de este, com o seu poder, ter aforado por 10000 réis o paúl de Atela, cujo valor de venda a câmara avaliava entre 18 e 20000 cruzados, embora com exagero, segundo parece, em relação às contas lançadas em receita no final do século anterior ${ }^{53}$.

A estratégia seguida por Miguel de Vasconcelos quanto a Santarém, assim como em relação às outras câmaras do primeiro banco de cortes, não foi apoiada pelo Marquês de la Puebla, que pretendia que o Secretário de Estado colocasse como vereador em Santarém um outro cunhado, de nome António Leite, guarda-mor das naus e armadas e morador em Lisboa.

Esta ideia de la Puebla era totalmente inviável, dadas as características das eleições dos vereadores em Portugal, motivo por que Miguel de Vasconcelos não aceitou a sugestão, susceptível, só por si, de amotinar o povo em virtude da sua não residência em Santarém, embora aceitasse, com relutância, que fosse nomeado o outro cunhado, morador no local, e outros eventuais afectos. Desta sua recusa foi Miguel de Vasconcelos acusado por la Puebla perante o governo de Madrid, assim como de outra omissão, o atraso do envio aos corregedores das comarcas das cartas para impor os referidos meios da renda fixa ${ }^{54}$.

s3 Capítulos de Santarém apresentados às cortes de 1642. O foro não parece ser fora do comum, considerando apenas o rendimento da lande, o qual atingia, em 1591, 8000 réis, de acordo com os dados publicados por Maria Angela V. da Rocha Beirante, Santarém Quinhentista. Lisboa, 1981, p. 161. A resposta régia a este capitulo limita-se a informar que a propriedade de Atela se encontrava confiscada, aconselhando a câmara a requerer justiça de modo ordinário, se pretendia ainda ter algum direito sobre ela.

${ }^{s 4}$ AGS, Estado, maço 4 047, múltiplos documentos; idem, maço 2 656, diversos documentos. Todos genericamente aproveitados em trabalhos que publiquei sobre a oposição política. Apresenta-se em apêndice um deles, o referente à carta de Miguel de Vasconcelos com data de 7 de Fevereiro de 1636. Uma outra carta, datada de 26 de Janeiro de 1636 e nomeada na anterior, foi já publicada por Mário Brandão, a partir de original conservado na Biblioteca Geral da Universidade de Coimbra (Ms. 1551, doc. 
A defesa de Miguel de Vasconcelos, datada de 7 de Fevereiro de 1636, espelha já muito bem as incompatibilidades e rivalidades existentes no governo de Lisboa, tendo então o Secretário de Estado colocado o lugar à disposição. A sua não demissão apressou, muito provavelmente, a recuperação da independência em virtude da progressão das desinteligências entre os membros do governo de Portugal, as quais, de acordo com a documentação conhecida, revelam um poder muito fragilizado pela pluralidade de mando desencontrado, certamente apoiado pelos que então, no seio da nobreza, se apelidadavam de populares, num tempo em que a cultura de corte e das cidades procurava estabelecer a diferenciação com o outro, os rurais e franjas citadinas. De qualquer modo, tanto as estratégias de Vasconcelos como as do Marquês de la Puebla não conseguiram o consenso universal (ou pelo menos suficientemente amplo) quanto à aceitação das novas formas contributivas, dado que os vereadores, embora representassem a cidade, não exprimiam a comunidade popular, tendo esta de ser ouvida em matéria que sobretudo lhe dizia respeito.

4. O governo das cidades, com efeito, não dependia apenas dos vereadores, recrutados dentro de um sector social restrito, o dos melhores. Governo de elites locais, necessariamente, mas com tons oligárquicos quando o exercício do poder se situava no interior de um pequeno grupo de famílias, e contra as quais por vezes lutou a comunidade $^{5 s}$. Vereadores que já nos princípios do século XVII

13), em Alguns documentos relativos a 1580, "Boletim da Biblioteca Geral da Universidade de Coimbra". 16, p. 62-73. Transcrevo em apêndice, do original, a parte que diz respeito a Santarém (doc. 2).

${ }^{55}$ Uma síntese recente sobre "o espaço político e social local", da autoria de Nuno Gonçalo Monteiro, in César Oliveira, História dos Municípios, cit., p. 121 s. Como muito bem tem acentuado José Viriato Capela, apoiado em boa documentação, a rotatividade dos eleitos nos pequenos concelhos era forçosamente muito maior. 
começavam a trocar a antiga designação de cidadãos pela de nobres, como as cortes de 1619 revelam ao solicitarem acrescentamentos para os fidalgos, mesmo os não filhados, esse novo estado do meio nobiliárquico.

Para além da gente da governança que se tratava à lei da nobreza, fazia-se ouvir a voz, e por vezes os votos, nas câmaras das cidades e vilas principais, dos representantes do povo politicamente considerado através da Casa dos Vinte e Quatro (ou dos Doze) e, eventualmente, pela intervenção espontânea ou não de representantes de outros sectores populares ${ }^{56}$. Audição sempre necessária em matéria contributiva, dada ainda a conotação existente entre tributário e vilão, entre não privilegiado e contribuinte.

$\mathrm{Na}$ conjuntura da imposição do referido aumento do cabeção das sisas e do real de água, a Casa dos Vinte e Quatro de algumas cidades, como aconteceu com a de Coimbra, procura organizar-se entre si e fazer frente aos vereadores, defendendo o povo, o que significa que em muitas cidades, como aconteceu na própria cidade de Évora, os Mesteres da mesa camarária assumem posição contrária aos vereadores. União de Mesteres que vamos de novo encontrar em 1660, por exemplo, em Coimbra, Leiria, Santarém, Tomar e Lisboa a propósito, mais uma vez, de matéria colectável ${ }^{57}$.

O movimento das comunidades políticas através dos seus representantes, em 1636, é já bem conhecido e revela o poder que originariamente as populações conservaram, não obstante a teoria do poder delegado que o centralismo elaborou para seu uso ${ }^{58}$.

${ }^{56}$ Sobre a organização paroquial de Entre Douro e Minho e o sentimento de comunidade, que leva muitas vezes o termo a opor-se à sede, à câmara, vide os trabalhos citados de José Viriato Capela sobre os municípios desta região c, recentemente. A Maria da Fonte na Póvoa de Lanhoso. Novos Documentos para a sua História. Póvoa de Lanhoso, Câmara Municipal, 1996.

${ }^{57}$ Sérgio Cunha Soares. O Município de Coimbra..., p. 528.

${ }^{58} \mathrm{O}$ pensamento jurídico que domina no chamado Estado de Ordens " concebia o 
A falta de consenso entre os dois poderes municipais, o dos vereadores e o da comunidade política, não permitiu, em 1635-1636, a redacção dos contratos com o poder régio, pelo que este se viu na necessidade de os impor por via coactiva, apelando aos direitos régios, às regalias. A resposta popular das cidades, vilas e seus termos não se fez esperar. A partir de 21 de Agosto de 1637 a revolta aberta eclodiu, tendo envolvido mais de metade da superfície de Portugal ao longo de cerca de seis meses.

A síntese da geografia da revolta, de acordo com a documentação que conheço no momento, localiza os movimentos sobretudo da margem direita do Tejo ao Algarve, com surtos no Norte do País e numa vasta zona que a partir do nordeste de Santarém se encaminha para a Serra da Estrela, tendo bem tocado pelo menos a Covilhã ${ }^{59}$.

Dentro desta geografia geral das terras revoltadas contam-se algumas do antigo termo de Santarém, como Golegã, Chamusca e Montargil, entre as já documentadas. Santarém, por sua vez, foi impedida de aderir ao movimento, segundo parece, em virtude de nela se instalar uma força militar que se movimentou em conjugação com um vasto plano repressivo dos levantamentos de 1637-1638.

A estratégia da pacificação dos levantamentos populares, que tiveram o apoio pela omissão e pela acção de facções da nobreza e do clero, demorou demasiado tempo a definir-se, reflectindo a gravidade da situação, que ultrapassou, numa segunda fase, o simples sacudir do jugo tributário, acabando a principal área revoltada por ser envolvida militarmente. Com efeito, dois exércitos foram canto-

poder político e o direito como algo que decorria directamente dum poder autoorganizador dos corpos sociais espontâneos, a família, as corporações e as cidades". A autonomiajurisdicional é substituída pelo poder delegado nos finais do Antigo Regime. (António Manuel Hespanha, Sábios e rústicos: a violência doce da razão jurídica, "Revista Crítica de Ciências Sociais", 25/26 (1986), p. 46-47).

${ }^{59}$ António de Oliveira, Poder e Oposição Política, cit., p. 166 s. 
nados junto das fronteiras portuguesas, um sediado em Ayamonte e outro em Badajoz, enquanto uma força militar, vinda de Cascais e Lisboa, comandada por Rui de Moura Cosme de Faria, subiu a linha do Tejo. Foi esta força militar que reduziu alguns lugares do Ribatejo, como pelo menos se verificou em Tancos, e que sustou o levantamento de Santarém, aboletando-se na vila, castigando-a como por antecipação em nome da memória da aclamação régia de 1580, o primeiro levantamento do período filipino em favor não das liberdades, mas da liberdade ${ }^{60}$.

5. Nos movimentos de 1637 tanto se levantaram camponeses como citadinos, tendo-se verificado no Algarve a junção de forças, onde os levantamentos parecem ter tido maior intenção política do que no Alentejo, pelo menos nos inícios. Mas tanto numa área como noutra, as cidades tiveram um papel decisivo na eclosão e configuração do movimento. Com efeito, no Alentejo aderiram as cidades de Portalegre, Évora e Beja e, no Algarve, todos os lugares principais se revoltaram, com excepção de Lagos ${ }^{61}$ Outras cidades do país, incluindo Ponta Delgada (e mesmo Luanda, sob pretexto das meias anatas), se agitaram entre 1629 e 1638, cabendo a Évora um lugar simbólico, onde então se encontrava D. Diogo de Castro, antigo Vice-Rei, que negociou directamente com Olivares, de modo muito empenhado, os termos do castigo a aplicar pela justiça régia ao crime de natureza política.

Évora, como se justifica a determinado passo do caminho para o castigo, não pretendeu rebelar-se, mas tão só defender os seus foros.

${ }^{60}$ António de Oliveira, Um documento sobre as "alterações" de 1637, "Revista Portuguesa de História,", tomo XI, Vol. II, 1968, p. 277-303; AGS, Secretarias Provinciais, Livro 1570, fl. 23.

${ }^{61}$ António de Oliveira, Levantamentos Populares do Algarve em 1637-1638. A Repressão. Coimbra, 1984. 
A violação das liberdades locais foi sempre e será um motivo de revolta, se bem que na conjuntura do movimento de 1637-1638 estava também em questão a liberdade global do reino, a qual orientou os levantamentos no sentido da recuperação da independência nacional.

Doravante, e até cerca de 1680, para citar números redondos, mais de uma concepção de estado se desenha. Uma delas, acentuando a teoria mediadora do poder da comunidade entre Deus e o rei, irá ser favorável às expressões representativas e participativas da nobreza e do povo, sendo o tempo do localismo, do regionalismo, onde a realeza, como acentuou o saudoso Prof. Borges de Macedo, é mais "uma ideia nacional do que uma realidade"62. O centralismo do escrivão da puridade no tempo de D. Afonso VI, por seu lado, retoma a ideia do prestígio monárquico e de um ambiente gobal, solicitando às câmaras sugestões para um melhor governo do reino. Os termos do parecer dado a D. Afonso VI em 1667 para renunciar e convocar cortes, mostra bem, no entanto, como uma determinada facção concebia ainda o poder da monarquia. Talvez a mesma que em 1674 pretendia fiscalizar as despesas do estado (para além de outros objectivos) e cujas veleidades D. Pedro II, pela força da facção que o apoiava, cortou cerce, dissolvendo a assembleia. Uma nova forma de estado do nobre-cortesão se acentua, a qual se vai reflectir no poder dos municípios, nomeadamente a partir dos anos quarenta do século XVIII, tempo em que a fidalguia das principais cidades, pelo menos, substitui o governo mais alargado dos melhores naturais e residentes e se comporta como um vassalo régio, impondo localmente o despotismo, que nem por ser iluminado deixa de ser uma grande escuridão, longinquamente afastadas como estavam as

${ }^{62}$ Jorge Borges de Macedo, História Diplomática Portuguesa. Constantes e Linhas de Força. Estudo de Geopolítica. Lisboa, Instituto de Defesa Nacional, s. d., p. 184 s.; idem, O Conde de Castelo Melhor. Ensaio Biográfico, in "Os Grandes Portugueses", Lisboa, p. 37-35. 
primícias do governo das comunidades medievais, situadas 900 anos atrás, comemorados a partir dos primeiros forais e da concessão da Terra Portucalense a D. Henrique. Arqueologia do poder autónomo das cidades e vilas que se pretende, de novo, repensar através da sua história e que o período filipino nos permite relembrar, com D. Francisco Manuel de Melo, que já em Évora, ao tempo dos levantamentos populares, nos apresenta uma democracia directa a dirigir o poder que então os populares controlavam, ao lado do poder dos vereadores e do poder monárquico, os três poderes de um governo misto que as cidades e as vilas souberam gerir, embora convivendo com mais do que uma concepção de Estado que por força se repercutia localmente. Com João Pinto Ribeiro, prefiro a soberania e majestade do poder das repúblicas, casado com o poder régio, do que a figura geométrica de periferia que faz desta uma administração local do Estado ${ }^{63}$.

\section{Será tempo de concluir.}

A nova participação política que se deseja na cidade em que se vive, a vivência dos novos valores de sempre, porque humanos, o exercício de poderes não estatais, postulam um novo modelo de Estado e, com ele, um reforço dos poderes da cidade, do poder local. Para esse poder local se voltam os homens em busca de se encontrarem, repensando o passado com que pretendem construir os sonhos. Sem estes não há futuro. Foram os sonhos, qual feitos loucura, que levaram António Baracho, aqui em Santarém, a apelidar a ideia da liberdade ${ }^{64}$, cujo eco de retorno final chegou sessenta anos

${ }^{63}$ Antonio Marongiu, Villes et Féodalités au Moyen Age, in "Villes de 1'Europe Méditerranéenne et de l'Europe Occidentale du Moyen Age au XIXe Siècle. Actes du colloque de Nice (27-28 mars 1969), p. 13. (Volume dos "Annales de la Faculté des Lettres et de Sciences Humaines de Nice", nº 9-10 (1969).

${ }^{64}$ Joaquim Veríssimo Serrão, O Reinado de D. António Prior do Crato. Volume I (1580-1582). Coimbra, 1956, p. 19. 
depois. O presente, como ensinava Santo Agostinho, é o presente das coisas passadas, presentes e futuras. Sábia conjugação do tempo presente, esse "futuro do passado", como definia Fernando Pessoa. O centro das nossas vidas não é um ponto geométrico da periferia, mas sim o centro do poder, o qual passa pela construção das novas cidades em tempo da segunda revolução democrática, a qual implica a globalização, matriz do local e da indigenização das culturas infranacionais. 


\section{APÊNDICE DOCUMENTAL}

1636, Fevereiro, 7 - Lisboa

Carta de Miguel de Vasconcelos defendendo-se perante o monarca de varias acções e omissões que the são imputadas no desempenho de funções públicas, nomeadamente no que diz respeito à câmara de Santarém.

(Arquivo Geral de Simancas, Estado, maço 4 047)

Señor

En carta de 25 de Enero pasado me diçe Vuestra Magestad que la umision que ha avido de mi parte en remitir los despachos a las camaras del Reino para lo que toca a el real de agua y quarta parte del cabeçon si fuese como se ha representado a Vuestra Magestad seria cosa en que el serviçio de Vuestra Magestad abria padeçido mucho perjuiçio y que assi autenticamente abisare a Vuestra Magestad el dia que los firmo la Señora Prinçessa y copia de las partes con que se remitieron a las camaras diçiendo particularmente que causa huvo para detenerlos y si fue con orden o sabiduria de Su Alteza para que entendiendo Vuestra Magestad como satisfago a todo y particularmente quede Vuestra Magestad enterado de lo que en esto ha pasado y que tambien estrañaria Vuestra Magestad mucho si fuese çierto el haver dexado de acetar un pariente mio el offiçio de vereador de Santaren en ocasion que podria ser tan del serviçio de Vuestra Magestad que persona que dependiese de mi acudiese a lo que se ofrezea del y que ansi lo havisare luego con puntualidad y que causa huvo para dexar de açetar.

Mucho es Señor que siendo el negoçio del desempeño el en que pensava que yo havia mereçido mas aya quien con semejantes informaçiones trate de me haçer culpas ante Vuestra Magestad en esto no tengo que deçir a Vuestra Magestad sino remitirlo a Dios a quien es presente el yntento y animo de cada uno y a las aberiguaçiones que Vuestra Magestad fuere servido mandar haçer 
por las quales constara a Vuestra Magestad que me he ajustado con la obligaçión de su real serviço y la calidad del zelo de quien me quiere arguir en ellas.

Al punto que recevi la carta de Vuestra Magestad procure los portes de los correos que se havian despachado con las ordenes sobre el real de agua y cabeçon para satisfaçer a lo que Vuestra Magestad me manda pelo como esto fue en Septiembre y en el fin de cada mes juntos los portes de los correos que en el se despacharon con las certificaçiones de sus diligencias reconoçidos por un contador y provedor de quentas y sumado lo que se gasto en el dicho mes se da despacho al correo mayor para se le haçer pagamento diçiendose en el mismo despacho que los portes se rompieron al firmar como se haçe que es conforme a las ordenes de Vuestra Magestad previniendose con esto que no se pueda pedir otra vez pagamento duplicado y assi constara a Vuestra Magestad por la certificaçion jurada que va inclusa del theniente del correo mayor con quien heçe diligençia para satisfaçer a lo que Vuestra Magestad me manda.

Pero Señor es tal mi vigilançia y cuidado con que obro asi por lo que toca al serviçio de Vuestra Magestad como por los emulos que tengo por el dicho respeto que lo que nunca se hizo en esta Secretaria ordene se hiçiese despues que ha que sirvo en ella y fue que los despachos que desta Secretaria se embian al correo mayor firma su theniente al pie de una lista que se haçe de como quedan en su poder y la que toca a este particular imbio originalmente a Vuestra Magestad para que conste a Vuestra Magestad del dia que estos despachos del real de agua y cabeçon se llevaron para expedir los correos que fue en $\mathbf{1 5}$ de Septiembre siendo las fechas de las cartas que la Señora Prinçessa firmo de 13 del dicho de forma que solo huvo dos dias en medio en los quales se travajo de manera que se bençio en ellos lo que pareçia inposible en muchos porque en registar las dichas cartas para todo el Reino y reconoçer los papeles que se embiaron con ellas tirar copias de las que se havian escripto a las camaras que se remitieron a los corregedores y proveedores firmadas por mi ajustar las instruçiones de la junta abia menester muchos dias y en solos dos se hiço todo y mas porque reconoçiendo los despachos que se havian hecho en la Junta repare en algunas cosas que podian causar confusion no se declarando a los dichos corregedores y proveedores en el modo que era neçessario comunicando esto al Marques de la Puebla y al obispo de Targa y caiendo ellos en lo preçisso 
destas declaraçiones y con su orden los hiçe yo por otras cartas mias a todos los corregidores y proveedores en los mismos dos dias para mayor brevedad del negoçio porque si se huviera de comunicar en la Junta se detubiera algunos dias anteponiendo este negoçio al despacho del correo ordinario que concurrio en el mesmo dia de 15 de Septiembre, y por la çertificaçion jurada del Padre Luis Servera offiçial maior de la misma Junta del Desempeño que va con esta por quien corren los papeles de la dicha Junta a quien el Marques de la Puebla llama y da las ordenes que le pareçe constara a Vuestra Magestad lo que queda referido y otra del obispo de Targa por la qual mas particularmente mandara Vuestra Magestad ver el cuidado y prontitud con que en estos negoçios tengo servido y expidiente con que asisto a ellos.

$Y$ enquanto a lo que contiene la segunda parte de la carta de Vuestra Magestad y que mi pariente no quiso açetar ser vereador de Santaren digo Señor que tanto que llego la Señora Prinçessa a esta çiudad como yo dejava ajustado en la de Evora lo que en ella esta executado trate luego de disponer lo mismo en Santaren para lo que hiçe venir aqui las personas de quien podia fiar este negoçio y se lo comunique y representandolo assi al Marques de la Puebla tuvo por mejor sin embargo de todo que con los vereadores que servian y estan sirviendo que eran los mismos que se havian opuesto a este negoçio en los goviernos pasados del Conde de Crasto y Don Diego de Castro se tratase siguiendose desta resoluçion del Marques no solo no se haver conseguido lo que se queria mas dificultarse mas el negoçio con no consentir aquella camara y quiça de que de yo tener mis deudos çiertos para haçer el serviçio de Vuestra Magestad fuese mucha parte de se embiar a Santaren un oydor buscandose para esto uno tan mal afecto a mis cosas que fue recusado por sentençia $y$ finalmente un deudo mio que estava embarcado para el Brasil por capitan de un galeon y que havia ya hecho en compañia de Don Antonio de Oquendo le prendieron por una culpa que resulto de la dicha pesquisa que havia acaeçido çinco años atras y que quando mucho della podia resultar condenaçion de ducientos cruçados y murio de un tavardillo que le dio en la carçel anteponiendose al serviçio de Vuestra Magestade el respecto con que todo se hiço de que Dios dara el pago a quien lo mereçe siendo que neste mismo tiempo con parecer del Marques de la Puebla sacaron presos de los carçeles 
para embarcar en la armada como se hiço estando muchos dellos por casos graves evidente prueba del fin con que en esto $y$ en las mas cosas que me tocan se camina.

Agora en los ultimos de Diçiembre segun mi memoria me dijo el Marques de la Puebla porante la Señora Prinçessa que convenia tratar desto de Santaren como yo primero lo havia dispuesto respondile que por lo que me tocaba y a mis cosas estava prontisimo porque mi boluntad era solamente el serviçio de Vuestra Magestad aun que se podia considerar la alteraçion que despues acá havia avido negando aqella villa o no consintindo en los medios que Vuestra Magestad mando executar a lo que el Marques me respondio que fuese vereador mi cuñado Antonio Leite a lo que le dije que no siendo el dicho Antonio Leite morador en Santaren antes teniendo su cassa en Lisboa y estando exerçiendo en ella el offiçio de guarda mayor de las naves y armadas no podia ser vereador en Santaren ni lo consentirian por ser contra las leyes y ordenanças y se amotinaria el pueblo demas que esto solo seria bastante para se desencaminar lo que se pretendia y que no obstante esto que si el Marques entendia que convenia entrar cuñado mio que yo tenia en la dicha villa uno hermano deste mismo el qual vivia en ella y que fue uno de los que al prinçipio llame que podria serlo pero que havia que considerar si convenia haçerse cuñado mio porque se entendria que se nombrava con este yntento y podria haver alteraçion en el pueblo porque el negoçio estava en diferente estado que al prinçipio en que se no hiço lo que yo apunte y que sin embargo de todo si pareçiese al Marques seria vereador el dicho mi cuñado que vive en Santaren o que yo le nombraria personas que lo fuesen de quien se pudiese fiar el buen suçesso deste negoçio a lo que no difirio de forma Señor que el Marques no quiso en primer lugar se siguiese lo que le apunte y depues de se desencaminar el negoçio queria que fuese un cuñado mio que vive en Lisboa que no puede ser conforme las leyes y offreçiendole yo otro cuñado hermano del mismo en que no havia el dicho ynconviniente ni que se pudiese considerar que havia en nos otros respectos con las consideraçiones apuntadas como ya dije a Vuestra Magestad por otra carta de 26 de Enero no me ablo mas sobre esta materia como lo que digo paso en presensia de la Señora Prinçessa della podra Vuestra Magestad enterarse de la verdad y assi solo lo que puedo deçir en esta materia es que 
Dios save el zelo y animo con que sirvo a Vuestra Magestad.

En los primeros de Enero recivi una carta que Vuestra Magestad fue servido mandarme escrivir encargandome este negoçio con la camara de Santaren y dando quenta della a la Señora Princessa y al Marques de la Puebla como Vuestra Magestad me mandava fue de pareçer el Marques que ella se remitiese a la Junta del Desempeño con lo que el negocio quedo publico y en terminos que es mucho para considerar se conviene al serviçio de Vuestra Magestad que yo entre en esta materia porque no sea esto mismo parte para que el negocio se desencamine mas como lo represente a Vuestra Magestad en la carta de veinte y seis de Enero de manera que haciendome Vuestra Magestad merced en la misma carta mandar de me decir la satisfacion con que yo havia procedido en esta materia eso mismo fue parte para se me querer deslucir lo que yo havia obrado con la informaçion que se dio a Vuestra Magestad.

Por lo que queda referido sera presente a Vuestra Magestad lo que he pasado en las dos cosas que contienen la carta de Vuestra Magestad y aun que de la mayor justificaçion que Vuestra Magestad sea servido que yo de de mi proceder recivo en ello particular merced contodo postrado a los reales pies de Vuestra Magestad con toda la sumision devo representar a Vuestra Magestad que siendo los cargos que se me oponen de umision y haviendo yo procedido con el cuidado y zelo que se ve pues en uno dentro en dos dias se obro lo que se no podia hacer en muchos $y$ en el otro no falte estando pronto por mi parte que es mucho para reparar el animo de quien me quiere desacreditar con Vuestra Magestad y lo que haria si huviesse otra cosa en que hacerlo y el riesgo en que estoy metido porque siendo inferior ni puedo andar tan acautelado que aya de tener los descargos por scripto quando muchas ordenes se me dan de palabra y no puedo pedirlas muchas veces en otra forma o porque en racon de offiçio se me deve dar credito o porque si las pedir al Marques por escripto me podia tratar de la manera que hico en otras ocasiones como ya represente a Vuestra Magestad porque aun la Señora Princessa pidiendole algun parecer por scripto no lo da y assi buelvo otra vez postrado a los reales pies de Vuestra Magestad poner en consideraçion a Vuestra Magestad si conviene a su real servicio ocupar yo este puesto o mandar Vuestra Magestad lo que fuere mas conviniente a su servicio que este es mi principal intento esperando de la grandeca de Vuestra 
Magestad mandara tener quenta con mi reputaçion. Guarde Dios la catholica persona de Vuestra Magestad. Lisboa a 7 de Hebrero de 1636.

Miguel de Vasconselos e Britto [Ass.]

1636, Janeiro, 26 - Lisboa

Extracto de uma carta de Miguel de Vasconcelos onde se refere a ordem secreta que lhe foi dada para negociar com a câmara de Santarém.

(Biblioteca Geral da Universidade de Coimbra, $m s$. 1551, doc. 13). Pub. na íntegra por Mário Brandão, Alguns documentos relativos a 1580, "Boletim da BGUC", 16, pp. 62-73)

[...] Mandandome Vuestra Magestad escrivir en secreto sobre façilitar la camara de Santaren para esto de la renda fija y dando quenta de la carta a la Señora Prinçessa conforme la orden de Vuestra Magestad y al Marques de la Puebla como ago en todo fue de pareçer el Marques que la carta se remitiese a la Junta del Desempeño con lo que quedase publico como lo es que yo soy lo que hede haçer que la camara de Santaren benga en este serviçio que es el camino para me ynposibilitar el poder haçerlo porque esto consiste en la maña y en el secreto como hiçe con la camara de Evora sin rumor como es presente a Vuestra Magestad y berificase mas esto con que apuntando yo al Marques tres personas para bereadores de Santaren con que el negoçio se façilitaria no quiere sino que sea un cuñado mio para que el pueblo entienda que yo hago este negoçio y se errite contra mi cuñado con que yo quede con desaire y el negoçio se no haga por mi via y generalmente se entiende como se diçe por aca que yo el secretario Diogo Soarez mi cuñado somos los que haçemos todo esto de la renda fixa contra el pueblo y quiçá a Vuestra Magestad podran escrivir que ellos lo haçen todo pero Señor quede Vuestra Magestad servido en este negoçio que es mi intento y digan lo que quisieren. [...]

Miguel de Vasconselos e Britto [Ass.] 